which lie in the embrace of the river's curve. To the unwary visitor, these appear attractive for residence, or at the least for the week-end bungalow, but are in fact unfitted for any dwelling-place. The ground is always waterlogged at a level little below the surface and is in most cases liable to flood, so that the site is unhealthy for the occupant. A still more important drawback is the difficulty of providing for disposal of sewage and of preventing contamination of the river. It is needful, moreover, that the river should be allowed to spread over these meadows in seasons of heavy rain, thus preventing sudden and excessive rise of level in the lower reaches.

When we turn from the hygienic to the sesthetic aspect of the matter we find that it is a requirement of scenic grouping, or 'landscape composition', to keep these broad, flat meadows free from buildings, for they are the foil of riverside towns and wooded bluffs, and also essential to the prospect from the opposite, higher bank, from which we obtain the wider view of the Thames Valley and its background of distant hills.

The Council for the Preservation of Rural England has only been in existence for three years, but its influence upon public opinion is already so great that there is every reason to hope that the proposals put forward on behalf of its Thames Valley branch will receive careful and sympathetic consideration.

Vaughan Cornish.

\section{Fossil Brains.}

Die fossilen Gehirne. Von Tilly Edinger. Pp. 249. (Berlin : Julius Springer, 1929.) 36 gold marks.

r THE best results in seience have been obtained 1 mostly by combining two hitherto separate branches or methods. The author of the work before us is a daughter of the late Prof. Ludwig Edinger, who is well known as one of the founders of the comparative anatomy of the brain. She grew up, therefore, in a very centre of comparative neurology, and having also studied palæontology from the geological point of view, she joined these two branches in a remarkable manner in palceoneurology, which is not an entirely new combination, but has never been practised so thoroughly and methodically. The chance to make errors in this field is greater than anywhere else. For, as the author acknowledges in the very beginning of her book, a fossil thigh-bone is a thigh-bone anyhow, but a 'fossil brain' is not a brain at all : it is-with a few exceptions-only a natural (petrified) or artificial endocranial cast of a fossil skull. By this fact we know more of the central nervous system of many fossil animals than, for example, of their intestines, but to interpret the data with accuracy we must begin by studying in recent animals the relations between the brain and the form of the endocranial cavity, which is in many cases much more spacious than would be necessary to contain the brain only. These and other methodical and technical matters are discussed in detail and elucidated with many illustrations in the general part (pp. 9-100) of the book.

Dr. Edinger has tried to write a clear and instructive book for neurologists, for whom so many names of geological periods and fossil animals are mere 'words' as well as for palæontologists not versed in the neurological "jargon'; and in this she has been successful.

The other part of the book is a copiously illustrated critical compilation (classified according to the zoological system) of all that is known about the central nervous system of fossil vertebrates; and it is more than a compilation only, for the author, guided by her great experience on the subject, often gives her own interpretation of the facts. The alphabetical bibliography (250 entries!) has the practical feature that not only are the titles cited, but also with every article a brief mention is made of what it contains referring to the subject in question.

In conclusion, some of the problems of general interest dealt with in the chapters may be mentioned. Marsh's 'law' suggesting that the species that proved to be the 'fittest to survive' had comparatively larger brains than the extinct forms, is not generally confirmed. Technical masterpieces of palæoneurology are the reconstructions of the endocranial cavity with all canals and openings in fossil fishes, made by Stensio. It is confirmed that some of the giant forms among fossil animals had small brains, but a relatively giant hypophysis. The sacral dilatation of the spinal canal in Stegosaurus is discussed in detail. The brain of the flying reptiles (Rhamphorhynchoidea and Pterodactyloidea) had many bird-like features, while the brain of the contemporary Archoopteryx was still more of the reptile type. The typical form of the bird's brain seems to be in connexion with the function of flying. Like other organs also, the fossil brains make it clear that both birds and mammals have developed gradually from reptiles; this evolution is partly a relative increase of the fore-brain. The brains of fossil Anthropoidea are described in a special chapter.

P. J. VAN DER FEeN, JR. 